\title{
3-6 Yaş Çocukları İçin Öz Bakım Becerileri Değerlendirme Testi: Geçerlik Ve Güvenirlik Çalışması
}

\author{
The Assessment of Self Care Skills Test For 3-6 Year Old Children: \\ Reliability and Validity \\ Ayça BAYER ${ }^{1}$ \\ Aysel ÇAĞDAŞ ${ }^{2}$ \\ Gökhan KAYILI ${ }^{3}$
}

• Geliş Tarihi: 23.01.2019 • Kabul Tarihi: 25.06.2019 • Çevrimiçi Yayın Tarihi: 15.07.2019

\section{$\ddot{\mathbf{O z}}$}

$\mathrm{Bu}$ araştırmanın amacı 3-6 yaş çocuklarının öz bakım becerilerini değerlendirmeye yönelik bir ölçme aracı geliştirmektir. Araştırmanın örneklemini tesadüfi küme örneklem yoluyla seçilen iki özel ve dört resmi okul öncesi eğitim kurumuna devam eden 211 çocuk oluşturmuştur. Testin geçerlik çalışmasında; yapı geçerliği ve kapsam geçerliği analizi işlemleri uygulanmıştır. Açımlayıcı faktör analizi sonuçlarına göre testten madde çıkarımı yapılmamış ve test toplam 50 maddeden oluşmuştur. Ayrıca kapsam geçerliği sonucunda uzmanların önerileri doğrultusunda test altı alt başlık (temizlik ve kişisel bakım, yemek yeme, dinlenme, giyinme, kendini kazalardan koruma, çevreyi düzenleme) altında toplanmıştır. Testin uygunluk indeksini test etmede Maksimum Olabilirlilik Doğrulayıcı Faktör Analizleri kullanılmıştır. Elde edilen uyum indeks değerleri, ölçek maddelerinin alt testler için uygun şekilde tayin edildiğini göstermiştir. Testin güvenirlik çalışması için iç tutarlık katsayısı, test-tekrar test güvenirliği ve iki yarı test güvenirliği işlemleri kullanılmıştır. Testin üç, dört, beş ve altı yaş için ayrı ayrı hesaplanan Cronbach Alpha güvenirlik katsayısı değerlerinin yüksek olması, yapılan test-tekrar test uygulamasından elde edilen sonuç ve Spearman Brown katsayıları, testin güvenirliği bakımından yeterli olduğunu göstermiştir. Araştırma sonucunda elde edilen genel sonuç; Öz Bakım Becerileri Değerlendirme Testi'nin üç-altı yaş çocuklarının öz bakım becerilerini değerlendirmek için geçerli ve güvenilir bir ölçme aracı olduğudur.

Anahtar sözcükler: Okul öncesi eğitim, öz bakım, geçerlik, güvenirlik

Atıf:

Bayer, A., Çağdaş, A. ve Kayılı, G. (2020). 3-6 yaş çocukları için öz bakım becerileri değerlendirme testi: Geçerlik ve güvenirlik çalışması. Pamukkale Üniversitesi Ĕgitim Fakültesi Dergisi, 48, 234-251. doi: 10.9779/pauefd.516623

\footnotetext{
${ }^{1}$ Uzm. Öğrt., Selçuk Üniversitesi, ayca_bayer@hotmail.com.tr, Orcid ID: 0000-0001-6936-5866

2 Dr. Öğr. Üyesi, Selçuk Üniversitesi, aysel_cagdas@hotmail.com, Orcid ID: 0000-0002-2766-1058

3 Doç. Dr., Selçuk Üniversitesi, gokhankayili@selcuk.edu.tr, Orcid ID: 0000-0001-7959-4128
} 


\begin{abstract}
The aim of this research is to develop a tool to measure the self-care skills of 3-6 years-old preschoolers. The Sample included 211 children from randomly-chosen two private and four public preschools. The Validity of the test was ensured by construct and content validity analyses. Based on the explanatory factor analysis, no item was excluded and the test consisted of 50 items. Also, the test was divided into six sub-categories (hygiene and self-care, eating, relaxation, dressing, self-protection from accidents, arrangement of environment) based on expert views. Maximum Likelihood Confirmatory Factor Analysis was done to test the goodness-of-fit index. The fit-index values showed that test items were assigned suitably of the subtests. Internal consistency coefficient, test-retest reliability and split-test reliability were used for the reliability of the test. High Cronbach's Alpha coefficients computed separately for three, four, five and six year olds, the result of the test-rest analysis and Spearman Brown coefficients revealed satisfactory values for the reliability of the test. The results concluded that The Assessment of Self-Care Skills Test is a valid and reliable tool designed to measure self-care skills of three to six year-old children.
\end{abstract}

Keywords: Pre-school education, self-care, validity, reliability

\title{
Cited:
}

Bayer, A., Çağdaş, A. \& Kayılı, G. (2020). The assessment of self-care skills test for 3-6 years old children: Reliabilit and validity. Pamukkale Üniversitesi Eğitim Fakültesi Dergisi, 48, 234-251. doi: 10.9779/pauefd.516623 


\section{Giriș}

Okul öncesi dönem, gelişmenin oldukça hızlı olduğu bir dönemdir. İlk bir yılda çocuğun uyku, yemek, temizlik gibi temel yaşam faaliyetleri belirli bir düzene girerken ilerleyen zamanda çocuğun vücudunu kontrol etmedeki başarısı giderek artar ve temel ihtiyaçlarını doğru olarak karşılamayı öğrenir (Oktay, 2006; Senemoğlu,1994;). Çocukların temel ihtiyaçlarını doğru olarak karşılamayı öğrenmeleri, sağlıklı bir hayat sürmelerinde önemli bir rol oynar (Aydoğmuş vd., 2010). Bireyin kendisi ile ilgili ihtiyaçlarını (yemek yeme, tuvalet ihtiyacı, kişisel bakım, güvenliğini sağlama vb.) kendisinin yapabilmesi yeteneği alan yazında öz bakım becerileri olarak adlandırılır (Oktay, 2002). Öz bakım becerileri bir anlamda günlük yaşam becerileridir. Günlük yaşam becerileri evde, okulda ya da diğer ortamlarda bireyin bağımsız olarak yaşamını sürdürebilmek, kişisel bakım ve görünüşünü koruyabilmek için gerekli olan tüm becerilerdir (Varol, 2005).

Bir çocuğun öz bakım becerilerini kazanmasındaki amaç, günlük temel ihtiyaçlarını kendi başına giderebilmesidir. Çocuğun günlük yaşamında uygulamalarla kazandığı öz bakım becerileri, anne-babadan bağımsızlığın başlangıcını gösterip hayatını başkalarına bağımlı olmadan, özgürce sürdürme olanağı sağlar (Demirel, 2008; Varol, 2014). Öz bakım becerilerinin gelişimiyle çocuğun sorumluluk bilinci güçlenir (Yavuzer, 2005). Uyku ve beslenme alışanlıkları ile tuvalet eğitiminin doğru biçimde kazanılması, çocuğun ileri yaşlarda sağlıklı bir birey olma şansını arttırır ve aile içi iletişimlerde olumsuz yaşantıları önleyerek, stres verici durumların azalmasında önemli rol oynar (Aydoğmuş vd., 2010). Bireyin kendine güven duymasına ve öz disiplin kazanmasına yardımcı olur (Mutlu vd., 2012). Olumlu sağlık davranışlarının ve kontrolün gelişmesinde, bireylerin kapasitelerinin artırılmasında ve yaşam kalitesinin yükseltilmesinde de öz bakım becerilerinin büyük etkisi vardır (Çimen ve Yavuz, 2007).

Birey hayatının ilk altı yılı içinde temel öz bakım becerilerini kazanır (Sarı, 2003). Bu dönem de öz bakım becerisi gelişmemiş bir çocuk kimi zaman sosyal ve toplumsal etkinliklere katılamamakta, çevresine yük olmakta sürekli kontrol altında tutulduğundan çevresiyle rahat iletişim kurma fırsatı bulamamaktadır (Konya, 2007). Çocuğa okul öncesi dönemde kazandırılacak öz bakım becerileri, onun gelecek yaşantısına güvenle bakılmasında etkili olur. Bu konuda bilinçli olarak verilen eğitimin katkıları büyüktür (Demiriz ve Dinçer, 2003). Normal gelişim gösteren çocukların yanında farklı gelişim gösteren çocukların da öz bakım becerilerini öğrenmesi için uygun eğitim tekniklerinin uygulanması önemlidir (Sarı, 2003).

Yapılan alan yazın incelemesi sonucu, çocuklarda öz bakım gelişimini inceleyen ölçme araçlarının sınırlı sayıda olduğu ve bu ölçme araçlarının kapsam bakımından geliştirilmesinin daha etkili sonuçlar ortaya koyacağı düşünülmüştür. Ayrıca bu yaş grubu çocuklarının öz bakım becerilerini öğretmen gözlem formu ile değerlendiren bir ölçme aracına Türkçe alan yazında rastlanmıştır ve sınırlı olduğu görülmüştür. Ancak ilkokul öğrencilerinin öz bakım becerilerini değerlendiren ölçme araçları mevcuttur (Altınsoy, 2008; Dinçer, Demiriz ve Ergül, 2017; Yılmaz, 2011). Bu bağlamda bu araştırmanın amacı; geliştirilen "3-6 Yaş Çocukları İçin Öz Bakım Becerileri Değerlendirme Testi (ÖBBDT)"'nin geçerli ve güvenilir bir ölçme aracı olup olmadığının sınanmasıdır. 


\section{Yöntem}

Araştırma, genel tarama modelinde desenlenmiş bir ölçek geliştirme ve geçerlik-güvenirlik çalışmasıdır. Genel tarama modelinde desenlenmiş araştırmalar var olan durumu var olduğu şekliyle aktarmayı amaçlayan araştırmalardır.

\section{Çalışma Grubu}

Bu araştırmanın verileri, 2013-2014 Konya ili merkez ilçelerinde (Meram, Selçuklu, Karatay) yer alan 2 özel ve 4 resmi okul öncesi eğitim kurumuna devam eden çocuklardan toplanmıştır. Araştırmaya dahil edilen okullar tesadüfi küme örnekleme yolu ile seçilmiştir. Araştırmaya 3-6 yaş aralığında toplam 211 çocuk dahil edilmiş, araştırmaya katılan çocukların 110'u kız (\%52.1), 101'i erkek (47.9) çocuklardan oluşmuştur. Araştırmanın çalışma grubunda yer alan çocukların 12 si üç (\%5.7), 51'i dört (\%24.2), 92'si beş (\%43.6) ve 56's1 altı (\%26.5) yaşındadır.

\section{Veri Toplama Aracı}

\section{Öz bakım becerileri değerlendirme testi}

Öz Bakım Becerileri Değerlendirme Testi 3-6 yaş çocuklarının öz bakım becerilerini değerlendirmek amacıyla geliştirilmiştir. Test çok yeterli, yeterli, orta, zayıf, çok zayıf kategorilerinden oluşan 5 aşamalı likert tipte yanıtlanan 50 maddeden oluşmaktadır. Test altı alt boyut (temizlik ve kişisel bakım "maddeler: 1,2,3,4,5,6,7,8,9,10,11,12,13,14,15,16,17,18"; yemek yeme "maddeler: 19,20,21,22,23,24,25,26,27,28,29"; dinlenme "maddeler: 30,31,32,33"; giyinme "maddeler: 34,35,36,37,38,39,40,41,42,43"; kendini kazalardan koruma "maddeler: 44,45,46"; çevreyi düzenleme "maddeler: 47,48,49,50" altında toplanmıştır.

Test sınıf öğretmenleri tarafından her çocuk için ayrı ayrı doldurulmaktadır. Çocukların aldığı her bir madde puanları toplanarak test puanları hesaplanmaktadır. Testten alınabilecek en yüksek puan; $50 \times 5=250$, en düşük puan ise $50 \times 1=50$ 'dir.

\section{Öz Bakım Becerileri Değerlendirme Testinin Geliştirilmesi}

Ölçek maddelerini oluşturmak için mevcut öz bakım becerileri ölçme araçları tespit edilmiş ve bu araçlardaki maddelerden yararlanarak testin bazı maddeleri hazırlanmıştır. Bu çalışma sırasında MEB'nın (2013) hazırladığı okulöncesi eğitim programı incelenmiş ve öz bakım becerisi ile ilgili kazanımlardan yararlanılmıştır. Ayrıca öğrencilerin bağımsız giyinme becerilerini ölçmek için geliştirilen pantolon, yakalı kazak ve çorap giyme beceri ölçü aracı (Vuran, 1989) ve denge eğitiminin öz bakım becerileri üzerindeki etkisini incelemek için geliştirilen denge ölçüm aracından yararlanılmıştır (Demirel, 2008). Farklı eğitim yöntemlerinde yer alan ve çocuklara öz bakım becerisi kazandırmada etkili olduğu düşünülen materyaller incelenmiş, bunlardan elde edilebilecek kazanımlara da maddelerde yer verilmiştir. Oluşturulan maddeler madde havuzunda toplanmıştır. Daha sonra araştırmacılar tarafindan benzer ölçek maddeleri belirlenmiştir. Benzer ölçek maddeleri elenmiş ve ölçek 55 maddeden oluşmuştur. Kapsam geçerliği çalışması için hazırlanan form 5 çocuk gelişimi ve eğitimi uzmanı tarafından test maddelerinin ölçme aracının amacına uygunluğunu değerlendirmişlerdir ve uzmanların önerileri dikkate alınarak 55 olan madde sayısı 50’ye düşürülmüştür. 


\section{Ön Uygulama}

50 maddelik taslak test formu ön uygulama için 20 çocuğa uygulanmıştır. Bu ön uygulama ile ölçek maddelerinin çocuklar tarafından nasıl anlaşıldığı amaçlanmıştır. Ön uygulamaya katılan çocukların tümünün taslak test formunu anlayabildiği sonucuna ulaşılmıştır ve böylece taslak test formu uygulamaya hazır hale getirilmiştir.

\section{Verilerin Analizi}

Öz Bakım Becerileri Değerlendirme Testi'nin geçerliği; kapsam geçerliği ve yapı geçerliği yöntemleri kullanılarak incelenmiştir. Öz Bakım Becerileri Değerlendirme Testi’nin güvenirlik çalışması için test-tekrar test güvenirliği ve iki yarı test güvenirliği yöntemleri kullanılmıştır. Araştırma verileri SPSS 22.0 ve LISREL 8.80 veri analizi paket programı kullanılarak analiz edilmiştir.

\section{Bulgular}

\section{Öz Bakım Becerileri Değerlendirme Testi’nin Geçerliği}

Geçerlik, testin bireyin ölçmek istenen özelliğini ne derece doğru ölçtüğüyle ilgili bir kavramdır. Geçerlik teknikleri için değişik sınıflandırmalardan bahsedilebilir. Bu sınıflandırma içinde en çok tercih edilenler arasında yer alan, kapsam geçerliği ve yapı geçerliği tekniklerine araştırmada yer verilmiştir (Büyüköztürk, 2013).

\section{Öz bakım becerileri değerlendirme testi'nin kapsam geçerliği}

Kapsam geçerliliği, ölçme aracında bulunan maddelerin ölçme amacına uygun olup olmadığının ve ölçülmek istenen alanı temsil edip etmediğinin incelenmesidir (Karasar, 2013). Araştırmanın kapsam geçerliği çalışmasında, 5 çocuk gelişimi ve eğitimi uzmanı tarafından test maddelerinin ölçme aracının amacına uygunluğu değerlendirilmiştir. Uzmanların tamamı test maddelerinin amaca uygun olduğunu belirterek çeşitli önerilerde bulunmuşlardır. Uzmanların önerileri dikkate alınarak 55 olan madde sayısı 50'ye düşürülmüştür. Ayrıca dil ve anlatım bakımından gerekli düzeltmeler yapılarak test son halini almış ve testin kapsam geçerliği sağlanmıştır.

\section{Öz bakım becerileri dĕgerlendirme testi'nin yapı geçerliği}

Yap1 geçerliliği, testte ölçülmek istenen davranışı değerlendirmek amacıyla geliştirilen maddeleri, davranışı ölçüp ölçmediğini ya da doğru bir şekilde ölçebilme derecesini gösterir. Öz Bakım Becerileri Değerlendirme Testi'nin yapı geçerliliğini incelemek amacıyla açımlayıcı faktör analizi tekniğinden yararlanılmıştır. Verilerin faktör analizine uygunluğu Kaiser-MeyerOlkin (KMO) katsayısı ve Bartlett Sphericity Testi ile sınanmıştır. KMO katsayısı, örneklem büyüklüğünün faktör analizi için uygunluğunu ve yeterli olup olmadığını sınar. KMO katsayısı 1 'e yaklaşması verilerin analize uygun olduğu anlamına gelmektedir. Öz bakım Becerileri Değerlendirme Testi için KMO katsayısı değeri .837 olarak hesaplanmış, Bartlett Sphericity $\left(\mathrm{X}^{2}=765.635 ; \mathrm{p}<.01\right) \quad$ ve Chi-Square Testleri anlamlı bulunmuştur. Elde edilen sonuçlar doğrultusunda verilerin faktör analizi için uygun olduğu görülmüştür. Öz Bakım Becerileri Değerlendirme Testi'nin değerlendirdiği faktör ya da bileşen adı verilen yapıları ortaya çıkarmak amacıyla Temel Bileşenler Analizine dayalı olarak faktör analizi yapılmıştır. Analiz sonrasında 1'den büyük 6 faktörün olduğu gözlenmiştir ve yapılan kapsam geçerliliği 
çalışmasında ölçeğin altı alt boyutta değerlendirilmesinin daha sağlıklı sonuçlar vereceği görüşüne ulaş1lmıştır.

Tablo 1. Öz Bakım Becerileri Değerlendirme Testi Alt Boyutları ve Test Maddeleri Açımlayıcı Faktör Analizi Sonuçları

\begin{tabular}{|c|c|}
\hline Alt Boyutlar & Faktör \\
\hline Temizlik ve kişisel bakım & .781 \\
\hline Yemek yeme & .737 \\
\hline Dinlenme & .394 \\
\hline Giyinme & .730 \\
\hline Kendini kazalardan koruma & .588 \\
\hline Çevreyi düzenleme & .658 \\
\hline Test Maddeleri & Faktör \\
\hline 1. Ellerini sabunlar, durular, kurular. & .79 \\
\hline 2. Yüzünü yıkar, kurular. & .83 \\
\hline 3. Saçlarını tarar. & .72 \\
\hline 4. Tuvaleti geldiğinde kendiliğinden (uyarıya ihtiyaç duymadan) tuvalete gider. & .77 \\
\hline 5. Tuvalete yardımsız oturur. & .77 \\
\hline 6. Tuvaletini yaptıktan sonra tuvalet kağıdı kullanarak kişisel temizliğini yapar. & .82 \\
\hline 7. Tuvaleti temiz bırakır (sifonu çeker vb.). & .72 \\
\hline $\begin{array}{l}\text { 8. Diş firçasına yeterli miktarda macun alarak dişlerini firçalayıp yeterli miktar su ile } \\
\text { ağzını çalkalar. }\end{array}$ & .78 \\
\hline 9. Hapşırırken, esnerken, öksürürken ağzını kapatır. & .71 \\
\hline 10. Burnunu suyla ya da mendille sümkürerek temizler. & .64 \\
\hline 11. Ayakkabı bakımı yapabilir (ayakkabısını siler, boyar vb.). & .78 \\
\hline $\begin{array}{l}\text { 12. Küçük çamaşırları (mendil, toz bezi vb.) yeterli miktar temizleyici (sabun vb.) } \\
\text { kullanarak yıkar ve mandal kullanarak asar. }\end{array}$ & .77 \\
\hline 13. Aynada kendini inceleyip gerekli düzeltmeleri yapar (kıyafetini, saçını vb. düzeltir). & .72 \\
\hline 14. Dökülen kırıntıları süpürge ve faraş yardımıyla süpürür. & .82 \\
\hline 15. Çevresindeki ulaşımı kolay yerlerin (masa, sandalye, raf vb.) tozunu alır. & .81 \\
\hline 16. Beslenme için yiyeceklerin temizliğine dikkat eder. & .81 \\
\hline 17. Kirli tabak, bardak gibi birkaç parça bulaşığı temizleyici ürün (Sabun, deterjan vb.) & .76 \\
\hline 18. Giysilerinin temiz mi yoksa kirli mi olduğunu belirtir. & .77 \\
\hline 19. Yemek yerken çatal-kaşık kullanır. & .75 \\
\hline 20. Suyu bir kaptan diğerine dökmeden aktarır. & .71 \\
\hline 21. Servisteki yiyecekleri kepçe, spatula, vb. araçlar kullanarak tabağına alır. & .64 \\
\hline 22. Tabağına aldığı yiyeceği dökmeden götürür. & .68 \\
\hline 23. Bıçak kullanarak kesimi kolay malzemeleri (salatalık, domates vb.) keser. & .72 \\
\hline 24. Ekmeğin üzerine tereyağ, reçel vb. sürer. & .70 \\
\hline 25. Yemeğini dökmeden yiyip içer. & .68 \\
\hline 26. Yiyecek ve içecekleri ayrım yapmadan yiyip içer. & .76 \\
\hline 27. Yiyecekleri yerken sağlıklı-sağlıksız ayrımı yapıp sağlıklı yiyecekleri yer. & .82 \\
\hline 28. Yiyecekleri yerken görgü kurallarına uyar (ağzını kapatarak yer, peçete kullanır vb.). & .66 \\
\hline 29. Öğün zamanında ve süresinde yemeye özen gösterir. & .66 \\
\hline 30. Yorulduğu durumlarda dinlendirici bir etkinliğe katıllır. & .73 \\
\hline
\end{tabular}




\begin{tabular}{lc}
\hline 31. Dinlenme için gerekli hazırlı̆̆ı yapar. (tuvalete gider, pijama giyer vb.) & .83 \\
\hline 32. Dinlenme sonrası yatağını düzenler. & .83 \\
\hline 33. Dinlenme sonrası yüzünü yıkar. & .75 \\
\hline 34. Duruma ve hava koşullarına uygun giyeceği giyer. & .62 \\
\hline 35. Çıt çıt kapatır-açar. & .82 \\
\hline 36. Düğmeleri kapatır-açar. & .85 \\
\hline 37. Kopçaları takar-çıarır. & .85 \\
\hline 38. Fermuar kapatır-açar. & .84 \\
\hline 39. Kemer tokasını kapatır-açar. & .86 \\
\hline 40. Bağcıkları bağlar-açar. & .66 \\
\hline 41. Kıyafetini doğru şekilde giyer (ön-arka ayrımı yapar, baş ve kollara dikkat eder vb.). & .77 \\
\hline 42. Giysilerini katlar. & .77 \\
\hline 43. Giysilerini asar. & .73 \\
\hline 44. Tehlikeli olan durumlardan uzak durur (yetişkin olmadığı durumlarda da kendini & .61 \\
koruyabilir. Örn. Ateşe yaklaşmaz, ilaç-deterjan gibi maddelerden uzak durur vb. ). & .61 \\
\hline 45. Herhangi bir tehlike anında yetişkinlerden yardım ister (yangın, yaralanma vb.) & .56 \\
\hline 46. Acil durumlarda başvurulabilecek telefon numaralarını bilir. & .74 \\
\hline 47. Sınıf içindeki eşyaları (masa-sandalye vb.) çevresindekilere zarar vermeden ve gürültü & .80 \\
\hline 48. Kapıyı gürültü yapmadan açar-kapatır. & .83 \\
\hline 49. Oyuncakları ya da materyalleri kullandıktan sonra yerine yerleştirir. & .83 \\
\hline 50. İçinde bulunduğu çevreyi temiz tutar ve düzenler. & \\
\hline
\end{tabular}

Tablo 1'in değerleri incelendiğinde test maddelerinin faktör yüklerinin .56 ile .86 arasında değişiklik gösterdiği görülmektedir. Büyüköztürk (2013), faktör yükleri .30 ve daha yüksek olan maddelerin bireyleri iyi derecede ayırt ettiğini, .20-.30 arasında kalan maddelerin zorunlu görülmesi durumunda testten alınabileceğini veya maddenin düzeltilmesi gerektiğini, faktör yükleri .20'den daha düşük olan maddelerin ise testten çıkarılması gerektiğini belirtir. Bu sonuçlar referans alındığında ölçek maddelerinin tümünün ayırt ediciliği yüksek denilebilir. Bununla birlikte testten madde çıkarımı yapılmamış ve test toplam 50 maddeden oluşmuştur.

Öz Bakım Becerileri Değerlendirme Testi'nin faktöriyel yapısının doğruluğunun test edilmesi amacı ile doğrulayıcı faktör analizi işlemleri gerçekleştirilmiştir. Ölçek geliştirme çalışmalarında, açımlayıcı faktör analizinden sonra belirlenen faktör yapılarının doğruluğunun sınanması amacıyla doğrulayıcı faktör analizi işlemleri uygulanmaktadır. Öz Bakım Becerileri Değerlendirme Testi'nin uygunluk indeksini test etmede "Maksimum Olabilirlilik Doğrulayıc1 Faktör Analizleri" kullanılmıştır ve sekiz ayrı veri uygunluk indeksi hesaplanmıştır. Bunlar; Ki Kare $\left(\mathrm{X}^{2}\right)$, Serbestlik Derecesi $(\mathrm{Sd})$, Ki-Karenin serbestlik derecesine oranı $\left(\mathrm{X}^{2} / \mathrm{Sd}\right)$, Yaklaşık Hataların Ortalama Karekökü (RMSEA), İyilik Uyum İndeksi (GFI), Düzeltilmiş İyilik Uyum İndeksi (AGFI), Karşılaştırmalı Uyum İndeksi (CFI), ve Normlaştırılmamış Uyum İndeksi (NNFI)'dir (Şimşek, 2007). Tablo 2'de Öz Bakım Becerileri Değerlendirme Testi'nin Doğrulayıcı Faktör Analizi işlemleri sonuçları yer almaktadır. 
Tablo 2. Öz Bakım Becerileri Değerlendirme Testi’nin Doğrulayıcı Faktör Analizi Sonuçları

\begin{tabular}{ccccccccc}
\hline $\begin{array}{c}\text { Uyum } \\
\text { İndeksleri }\end{array}$ & & & & & & & & \\
& $\mathrm{X}^{2}$ & $\mathrm{Sd}$ & $\mathrm{X}^{2} / \mathrm{Sd}$ & RMSEA & GFI & AGFI & $\mathrm{CFI}$ & NNFI \\
\hline & 1371.54 & 1159 & 1.183 & 0.032 & 0.94 & 0.84 & 0.95 & 0.95 \\
\hline
\end{tabular}

Tablo 2 incelendiğinde, Öz Bakım Becerileri Değerlendirme Testi verilerine uygulanan doğrulayıcı faktör analizi işlemleri sonucunda; Ki-Kare $\left(\mathrm{X}^{2}\right)$ değeri 1371.54, Serbestlik Derecesi (Sd) 1159, Ki-Karenin Serbestlik Derecesine Oranı (X²/Sd) 1.183, Yaklaşık Hataların Ortalama Karekökü (RMSEA) 0.032, İyilik Uyum İndeksi (GFI) 0.94, Düzeltilmiş İyilik Uyum İndeksi (AGFI) 0.84, Karşılaştırmalı Uyum İndeksi (CFI) 0.95 ve Normlaştırılmamış Uyum İndeksi (NNFI) 0.95 olarak hesaplanmıştır.

Kabul edilebilir uygunluk derecesi, indekse göre farklılık göstermektedir. $\mathrm{X}^{2}$ ve $\mathrm{Sd}$ için, standart bir yorum yoktur, fakat genel kural, küçük değerler daha iyi bir uygunluk olduğunu göstermektedir. Modelin uyumluluğunun belirlenmesinde çoğunlukla Ki-Karenin Serbestlik Derecesine Oranı ile elde edilen değer kullanılmaktadır. Tablo 2'de Ki-Kare'nin Serbestlik Derecesine Oranı değerinin 1.18 olduğu görülmektedir. Bu değerinin 2 veya altında bir değer olmas1 modelin iyi bir model olduğunu 5 veya daha altında değer almas1 ise modelin kabul edilebilir bir uyum iyiliğine sahip olduğunu göstermektedir (Şimşek, 2007). Yaklaşık Hataların Ortalama Karekökü (RMSEA) değerinin 0.06'nın altında olması model için iyi bir uyum, 0.08 'in altında olması ise kabul edilebilir bir uyum iyiliği değeri olduğu ifade edilmektedir (Brown, 2006). Yaklaşık Hataların Ortalama Karekökü (RMSEA) değerine göre model iyi bir uyum sergilemektedir.

Kline'e (2010) göre model kabul edilebilir uyum iyiliği İyilik Uyum İndeksi (GFI), Karşılaştırmalı Uyum İndeksi (CFI), Normlaştırılmamış Uyum İndeksi (NNFI) değeri .90 veya bu değerden yüksek olmalıdır. Düzeltilmiş İyilik Uyum İndeksi (AGFI) değeri ise .80 civarında veya bu değerden yüksek olmalıdır. Elde edilen değerler incelendiğinde model kabul edilebilir uyum iyiliğinin yeterli olduğu görülmektedir. Diğer bir değişle Doğrulayıcı Faktör Analizi sonuçları modelin iyi bir uyum gösterdiğini kanıtlar niteliktedir.

Doğrulayıcı Faktör Analizi sonucunda elde edilen uyum indeks değerleri, ölçek maddelerinin alt testler için uygun şekilde seçildiğini göstermektedir. Doğrulayıcı Faktör Analizi sonucunda ortaya konulan Öz Bakım Becerileri Değerlendirme Testi'ne ilişkin standardize edilmiş path analizi sonuçları Şekil 1' de sunulmuştur. 


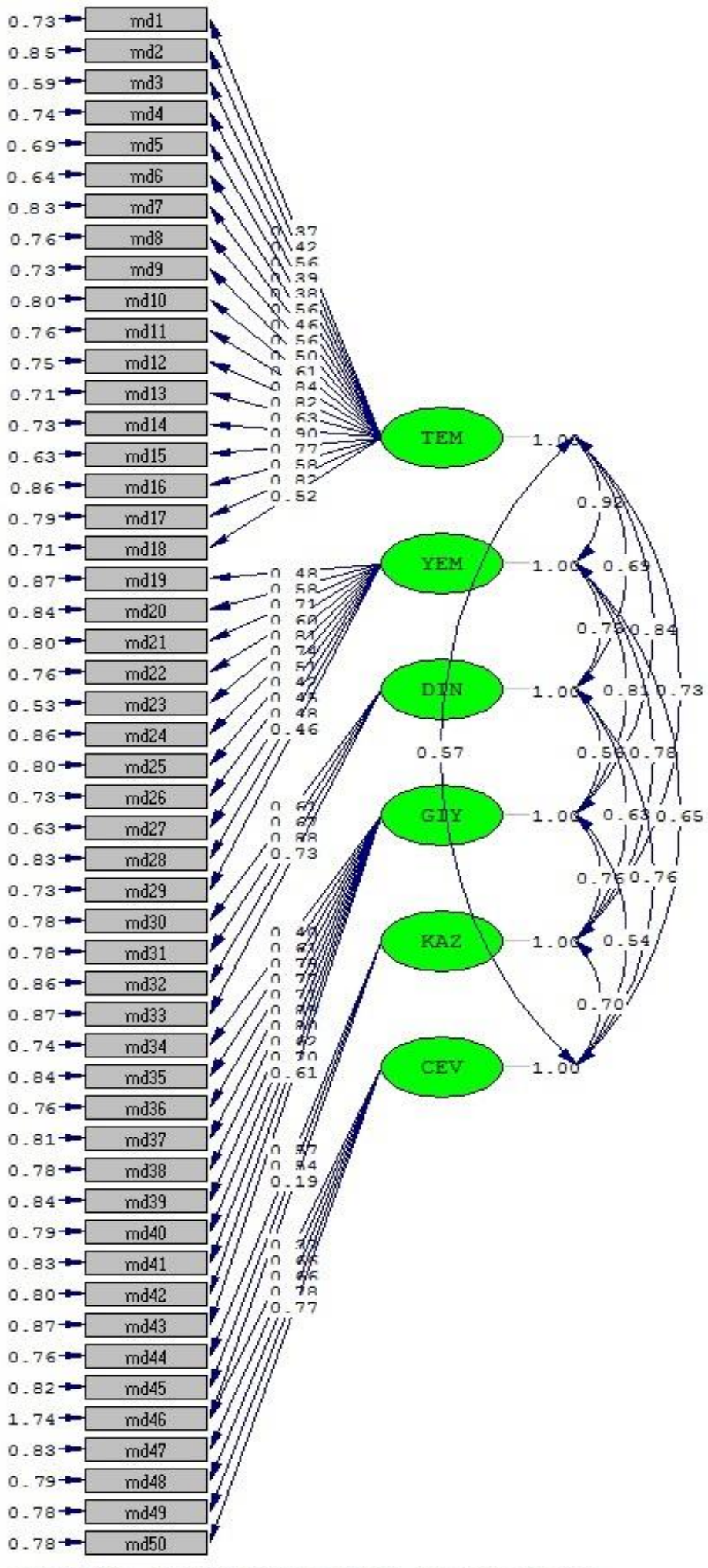

Chi-Square=1371.54, df $=1159, \quad P-v a l u e=0.00000, \quad$ RMSEA $=0.032$

Şekil 1. Öz bakım becerileri değerlendirme testi’nin doğrulayıcı faktör analizi sonuçlarına ilişkin standardize edilmiş çözümleme değerleri 


\section{Öz Bakım Becerileri Değerlendirme Testi’nin Güvenirliği}

Güvenirlik, bireylerin bir ölçme aracının maddelerine verdikleri cevapların tutarlılığı olarak tanımlanabilir ve ölçme sonuçlarının kararlılık derecesini gösterir. Güvenirlik, ölçme aracının ölçmek istediği özelliği ne derecede doğru ölçtüğü ile ilgilidir (Büyüköztürk, 2013). Araştırmada, Öz Bakım Becerileri Değerlendirme Testi’nin güvenirlik çalışması için, başlıca güvenirlik türlerinden iç tutarlılık güvenirliği, iki yarı test güvenirliği ve test-tekrar test güvenirliği teknikleri kullanılmıştır.

\section{Öz bakım becerileri dĕgerlendirme testi'nin iç tutarlık güvenirliği}

Öz Bakım Becerileri Değerlendirme Testi’nin iç tutarlık güvenirliğini hesaplamada Cronbach Alpha formülü kullanılmıştır. Yaş gruplarına ve test alt boyutlarına göre hesaplanan Cronbach Alpha formülüne ilişkin güvenirlik katsayılarına tablo 2'de yer verilmiştir.

Tablo 3. Öz bakım Becerileri Değerlendirme Testi Yaşlara Göre Cronbach Alpha Güvenirlik Katsayıları

\begin{tabular}{|c|c|c|c|}
\hline Yaş Grupları & Alt Boyutlar & Cronbach Alpa Katsayısı & $\begin{array}{c}\text { Alt Boyutlar } \\
\text { Toplamı }\end{array}$ \\
\hline \multirow{6}{*}{3 yaş } & Temizlik ve kişisel bakım & .93 & \multirow{6}{*}{.88} \\
\hline & Yemek yeme & .87 & \\
\hline & Dinlenme & .94 & \\
\hline & Giyinme & .97 & \\
\hline & Kendini kazalardan koruma & .69 & \\
\hline & Çevreyi düzenleme & .99 & \\
\hline \multirow{6}{*}{4 yaş } & Temizlik ve kişisel bakım & .95 & \multirow{6}{*}{.80} \\
\hline & Yemek yeme & .92 & \\
\hline & Dinlenme & .93 & \\
\hline & Giyinme & .93 & \\
\hline & Kendini kazalardan koruma & .68 & \\
\hline & Çevreyi düzenleme & .95 & \\
\hline \multirow{6}{*}{5 yaş } & Temizlik ve kişisel bakım & .96 & \multirow{6}{*}{.85} \\
\hline & Yemek yeme & .63 & \\
\hline & Dinlenme & .89 & \\
\hline & Giyinme & .96 & \\
\hline & Kendini kazalardan koruma & .77 & \\
\hline & Çevreyi düzenleme & .93 & \\
\hline \multirow{6}{*}{6 yaş } & Temizlik ve kişisel bakım & .95 & \multirow{6}{*}{.85} \\
\hline & Yemek yeme & .90 & \\
\hline & Dinlenme & .88 & \\
\hline & Giyinme & .90 & \\
\hline & Kendini kazalardan koruma & .42 & \\
\hline & Çevreyi düzenleme & .88 & \\
\hline
\end{tabular}

Tablo 2 incelendiğinde, üç yaş çocuklarına uygulanan Öz Bakım Becerileri Değerlendirme Testi'nin güvenirlik katsayısı .88, dört yaşa uygulanan Öz Bakım Becerileri 
Değerlendirme Testi'nin güvenirlik katsayısı .80 , beş yaşa uygulanan Öz Bakım Becerileri Değerlendirme Testi'nin güvenirlik katsayısı .85 ve altı yaşa uygulanan Öz Bakım Becerileri Değerlendirme Testi'nin güvenirlik katsayısı .85 bulunmuştur. Psikolojik bir test için hesaplanan güvenirlik katsayısının .70 ve daha yüksek olması test puanlarının güvenirliği için genel olarak yeterli kabul edildiği düşünüldüğünde, testin üç yaş, dört yaş, beş yaş ve altı yaş için ayrı ayrı hesaplanan Cronbach Alpha güvenirlik katsayısı değerlerinin yüksek olması testin güvenilir olduğunun bir göstergesidir (Büyüköztürk, 2013).

\section{Öz bakım becerileri değgerlendirme testi'nin test - tekrar test güvenirliği}

Test-tekrar test güvenirliği, bir testin aynı gruba belirli aralıklarla iki kez uygulanmasıyla elde edilen puanlar arasındaki korelasyon ile açıklanmaktadır. İki uygulama arasında ortalama dört haftalık bir sürenin geçmesinin genellikle uygun olduğu söylenilebilir (Büyüköztürk, 2013). Test dört hafta sonra 29 , beş yaş çocuğuna test tekrar test güvenirliği için öğretmenleri tarafindan tekrar doldurulmuş ve testin aralıklı tekrar korelasyonu .85 çıkmıştır.

\section{Öz bakım becerileri değgerlendirme testi'nin iki yarı test güvenirliği}

İki yarı test güvenirliği, testin maddelerinin tek-çift, ilk yarı-son yarı veya yansız olarak iki eş yarıya ayrılarak testin iki yarısı arasındaki ilişkiden hareketle Spearman Brown formülü kullanılarak hesaplanır (Büyüköztürk, 2013). Araştırmada Öz Bakım Becerileri Değerlendirme Testi'nin iki yarı test güvenliğinin hesaplanması amacıyla her alt boyutta yer alan test maddeleri iki yarıya ayrılmıştır ve Spearman Brown formülü kullanılarak her alt boyut için korelasyon katsayısı hesaplanmıştır. Yaş gruplarına göre hesaplanan Spearman Brown formülüne ilişkin güvenirlik katsayılarına tablo 3'de yer verilmiştir.

Tablo 4. Öz bakım Becerileri Değerlendirme Testi’nin İki Yarı Test Güvenirliği katsayıları

\begin{tabular}{clcc}
\hline Yaş Grupları & \multicolumn{1}{c}{ Alt Boyutlar } & Spearman Brown Katsayısı & Alt Boyutlar Toplamı \\
\hline \multirow{5}{*}{3 yaş } & Temizlik ve kişisel bakım & .71 & \\
& Yemek yeme & .77 & .79 \\
& Dinlenme & .81 & \\
& Giyinme & .83 & .78 \\
& Kendini kazalardan koruma & .78 & .82 \\
& Çevreyi düzenleme & .84 & \\
\hline \multirow{6}{*}{4 yaş } & Temizlik ve kişisel bakım & .81 & \\
& Yemek yeme & .84 & .83 \\
& Dinlenme & .86 & \\
& Giyinme & .86 & \\
& Kendini kazalardan koruma & .74 & \\
& Çevreyi düzenleme & .87 & \\
\hline \multirow{5}{*}{5 yaş } & Temizlik ve kişisel bakım & .84 & \\
& Yemek yeme & .74 & .85 \\
& Dinlenme & .88 & \\
& Giyinme & .78 & \\
& Kendini kazalardan koruma & .88 & \\
& Çevreyi düzenleme &
\end{tabular}




\begin{tabular}{llll}
\hline \multirow{6}{*}{6 yaş } & Temizlik ve kişisel bakım & .89 & \\
& Yemek yeme & .89 & \\
& Dinlenme & .88 & .88 \\
& Giyinme & .92 & \\
& Kendini kazalardan koruma & .85 & \\
& Çevreyi düzenleme & .86 & \\
\hline
\end{tabular}

Tablo 3'de görüldüğü üzere, Öz Bakım Becerilerini Değerlendirme Testi'nin üç yaş çocukları için iki yarı test güvenirlik katsayısı .79, dört yaş çocukları için .82, beş yaş çocukları için .83 ve altı yaş çocukları için .88 olarak hesaplanmıştır. Yaşlara göre elde edilen Spearman Brown katsayıları, testin iki yarı test güvenirliği bakımından yeterli olduğunu göstermektedir.

\section{Tartışma ve Sonuç}

Bu araştırmada, Öz Bakım Becerileri Değerlendirme Testi'nin üç-altı yaşındaki çocuklar için geçerlik ve güvenirlik analizlerinin yapılması amaçlanmıştır. Testin geçerlik çalışmalarında kapsam geçerliği ve yapı geçerliği yöntemleri kullanılmıştır. Kapsam geçerliği çalışmasında uzman görüşünden faydalanılmıştır ve uzmanların tamamı testin çocuklarda öz bakım becerilerini ölçmede amaca uygun olduğunu belirtmişlerdir. Yapılan öneriler doğrultusunda test maddeleri 55'den 50 maddeye düşürülmüştür. Testin yapı geçerliği çalışmasında, faktör analizi tekniğinden ve doğrulayıcı faktör analizi işlemlerinden yararlanılmıştır. Verilerin faktör analizine uygunluğu Kaiser-Meyer-Olkin (KMO) katsayıs1 ve Bartlett Sphericity Testi ile sınanmış, araştırma grubunun büyüklügünün faktör analizi için uygun ve yeterli olduğu sonucuna ulaşıılmıştır. Yapılan çalışmada Öz Bakım Becerileri Değerlendirme Testinin KMO katsayısı değeri .837 olarak hesaplanmıştır ve Chi-Square Test istatistiği anlamlı çıkmıştır. Elde edilen sonuçlar doğrultusunda verilerin faktör analizi için uygun olduğu görülmüştür. Testin faktörlerini ortaya çıkarmak amacıyla Temel Bileşenler Analizine dayalı olarak faktör analizi yapılmıştır ve analiz sonrasında 1'den büyük 6 faktörün olduğu görülmüştür. Bunun yanında yapılan kapsam geçerliliği çalışmasında da ölçeğin altı alt boyutta değerlendirilmesinin daha sağlıklı sonuçlar vereceği görüşüne ulaşılmıştır. Öz Bakım Becerileri Değerlendirme Testi'nin uygunluk indeksini test etmede Maksimum Olabilirlilik Doğrulayıcı Faktör Analizleri işlemleri kullanılmıştır ve sekiz ayrı veri uygunluk indeksi hesaplanmıştır. Uygulanan doğrulayıcı faktör analizi işlemleri sonucunda; Ki-Kare $\left(\mathrm{X}^{2}\right)$ değeri 1371.54, Serbestlik Derecesi (Sd) 1159, KiKarenin Serbestlik Derecesine Oranı $\left(\mathrm{X}^{2} / \mathrm{Sd}\right) 1.183$, Yaklaşık Hataların Ortalama Karekökü (RMSEA) 0.032, İyilik Uyum İndeksi (GFI) 0.94, Düzeltilmiş İyilik Uyum İndeksi (AGFI) 0.84, Karşılaştırmalı Uyum İndeksi (CFI) 0.95 ve Normlaştırılmamış Uyum İndeksi (NNFI) 0.95 olarak hesaplanmıştır. Kabul edilebilir uygunluk derecesi farklı kaynaklara göre değişiklik göstermekle birlikte $\mathrm{X}^{2}$ ve Sd için, standart bir yorum bulunmamaktadır. Ancak kabul edilen genel kural, küçük değerlerin daha iyi bir uygunluk gösterdiğidir. $\mathrm{X}^{2} / \mathrm{Sd}$ indeksi, makul bir uyum derecesi için beşten küçük olması (Brown, 2006), GFI, CFI, NFI, NNFI değerlerinin 90 veya bu değerden yüksek olması AGFI değerinin ise .80 civarında veya bu değerden yüksek olması beklenmektedir (Anderson ve Gerbing, 1984). Dolayis1 ile elde edilen uyum indeks değerleri, ölçek maddelerinin alt testler için uygun şekilde tayin edildiğini göstermiştir ve ortaya çıkan altı faktörlü yapı böylece doğrulanmıştır. Öz Bakım Becerileri Değerlendirme Testi’nin güvenirlik çalışması için iç tutarlık katsayısı, test-tekrar test güvenirliği ve iki yarı test güvenirliği işlemleri kullanılmıştır. Öz Bakım Becerileri Değerlendirme Testi'nin iç tutarlık 
güvenirliğini hesaplamada Cronbach Alpha formülü kullanılmıştır. Testin üç yaş çocukları için hesaplanan güvenirlik katsayısı .88 , dört yaş çocukları için hesaplanan güvenirlik katsayısı .80 , beş yaş çocukları için hesaplanan güvenirlik katsayısı .85 ve altı yaş çocukları için hesaplanan güvenirlik katsayıs1 .85 olarak bulunmuştur. Johnson ve Christensen (2014) ve Büyüköztürk (2013) iç tutarlılık için güvenirlik katsayının .70 ve üzeri olması gerektiğini; Coolican (2014) .75 ile 1.00 arasında olması gerektiğini; Balc1 (2015) .80 ve üstünde olmas1 gerektiğini belirtmişlerdir. Bu bilgilerden hareketle Öz Bakım Becerileri Değerlendirme Testi'nin iç tutarlılığının uygun değerlere sahip olduğu ve güvenilir bir ölçme aracı olduğu söylenebilir.

Öz Bakım Becerileri Değerlendirme Testi’nin güvenirliğine yönelik yapılan işlemler kapsamında zamana göre değişmezlik kriterini sağlayıp sağlamadığının sınanması amacıyla test-tekrar test uygulaması gerçekleştirilmiştir. Test birinci uygulamadan dört hafta sonra 29 beş yaş çocuğuna tekrar uygulanmıştır ve testin aralıklı tekrar korelasyonu .85 çıkmıştır. Testin iki yarı test güvenirliği işlemleri kapsamında ise iki yarı için Spearman Brown korelasyon katsayıları hesaplanmıştır. Üç yaş için .79 , dört yaş için .82 , beş yaş için .83 ve altı yaş için .88 korelasyon katsayısı bulunmuştur. Büyüköztürk (2013) korelasyon katsayısının mutlak değer olarak .70 ile 1.00 arasında olması yüksek, .70 ile .30 arasında olması orta, .30 ile .00 arası ise düşük düzeyde bir ilişki olarak tanımlamaktadır. Bu tanımlamaya göre Öz Bakım Becerileri Değerlendirme Testi'nin test-tekrar test ve iki yarı test güvenirliğinin yüksek düzeyde olduğu söylenebilir. Ayrıca elde edilen Spearman Brown korelasyon katsayıları çocukların yaşlarına paralel olarak doğru orantılı bir şekilde artmaktadır. Bu da gelişimin, her bir alanının farklı dönemlerde farklı hızlarda ilerleme kat etmesi ve gelişimde bir sıra vardır ilkesi ile açıklanabilir (Berk, 2006; Ungar, Ghazinour ve Richter, 2013). Araştırma sonucunda elde edilen genel sonuç; Öz Bakım Becerileri Değerlendirme Testi'nin üç-altı yaş çocuklarının öz bakım becerilerini ölçmek için geçerli ve güvenilir bir ölçme aracı olduğudur. Alan yazın incelendiğinde öz bakım becerilerini ölçmek amacıyla bazı veri toplama araçlarının geliştirildiği görülmüştür. Yılmaz (2011) tarafından ilköğretim öğrencilerinin öz bakım becerilerini ölçmek amacıyla İlköğretim Öğrencileri İçin Öz Bakım Becerileri Ölçeği geliştirilmiştir. Ölçek maddeleri belirlenirken çocuk gelişimi ile ilgili kaynaklardan ve MEB (2006) 36-72 Aylık Çocuklar İçin Okul Öncesi Eğitim Programı'ndan yararlanılmıştır ve araştırma sonucunda ölçeğin geçerli ve güvenilir bir ölçme aracı olduğu sonucuna ulaşılmıştır. Öz Bakım Becerileri Değerlendirme Testi'nin ölçek maddeleri oluşturulurken de MEB (2013) Okul Öncesi Eğitim Programı ve konu ile ilgili alan yazında yer alan araştırmalar ve farklı eğitim modellerinde yer alan öz bakım becerileri alıştırmaları temel alınmıştır. Dinçer, Demiriz ve Ergül'de (2017) Okul Öncesi Dönem Çocukları (36-72 ay) için Öz bakım Becerileri Ölçeği-Öğretmen Formu'nun geçerlik ve güvenirlik çalışmasını gerçekleştirmişlerdir. Çalışmada öğretmenlerin "Kişisel temizlik-tuvalet" ile ilgili öz bakım becerilerini diğerlerine oranla çok daha önemli buldukları saptanmıştır. Geliştirilen Öz Bakım Becerileri Değerlendirme Testi'nde de kişisel temizlik ve tuvalet ihtiyaçları ile ilgili maddelere yer verilmiştir. Alan yazın incelendiğinde çocuklarda öz bakım gelişimini inceleyen ölçme araçlarının sınırlı sayıda olduğu ve çalışmaların kapsam bakımından geliştirilmesi gerektiği görülmüştür. $\mathrm{Bu}$ çalışmanın alan yazına katk1 sağlayacağ düşünülmektedir. Ayrıca bu ölçme aracı 3-6 yaş çocuklarının öz bakım becerilerini ölçme bakımından da önem arz etmektedir. Geliştirilen öz bakım becerileri ölçeğinin, uygulanan okullarda çocukların öz bakım becerilerinin belirlenmesi ve yapılacak öz bakım becerileri ile ilgili diğer araştırmalara katkı sağlayacağı düşünülmektedir. 


\section{Kaynakça}

Altınsoy, M. (2008). Yatıll ilköğretim bölge okullarındaki yatılı ve gündüzlü ögrrencilerin kişisel bakımlarına ilişskin uygulamaları. Yayınlanmamış yüksek lisans tezi. Gazi Üniversitesi, Eğitim Bilimleri Enstitüsü, Ankara.

Anderson, J. C. \& Gerbing, D. W. (1984). The effect of sampling error on convergence, improper solutions, and goodness-of-fit indices for maximum likelihood comfirmatory factor analysis. Psychometrika, 49, 155-173.

Aydoğmuş, K., Baltaş, A., Batlaş, Z., Davaslıgil, Ü., Güngörmüş, O., Konuk,E., Korkmazlar, Ü., Köknel, Ö., Navaro,L., Oktay, A., Razon, N. ve Yavuzer, H. (2010). Ana-baba okulu. İstanbul: Remzi Kitabevi.

Balcı, A. (2015). Sosyal bilimlerde araştırma yöntem, teknik ve ilkeler (11. baskı). Ankara: Pegem Yayıncilık.

Berk, L. E. (2006). Development through the lifespan. Needham Heights, MA: Allyn and Bacon.

Brown, T. A. (2006). Confirmatory factor analysis for applied research series. New York, USA: The Guilford Press.

Büyüköztürk, Ş. (2013). Sosyal bilimler için veri analizi el kitabı. Ankara: Pegem Yayıncılık.

Coolican, H. (2014). Research methods and statistics in psychology (6th ed.). USA: Psychology Press.

Çimen, S. ve Yavuz, B. (2007). Serebral palsili çocukların öz bakım becerilerini gerçekleştirme düzeyleri ve etkileyen etmenlerin incelenmesi. C.Ü Hemşirelik Yüksekokulu Dergisi, 11, 17-26.

Demirel, N. (2008). Zihinsel Engelli Çocuklarda Denge Eğitimi Çalışmalarının Bazı Öz Bakım Becerilerine Üzerine Etkisinin İncelenmesi. Yayımlanmamış yüksek lisans tezi. Gazi Üniversitesi, Eğitim Bilimleri Enstitüsü, Ankara.

Demiriz, S. ve Dinçer, Ç. (2003). Okulöncesi Dönem Çocuklarının Öz Bakım Becerilerinin Annelerinin Çalışıp Çalışmama Durumlarına Göre İncelenmesi. Hacettepe Üniversitesi Eğitim Fakültesi Dergisi, $19,58-65$.

Dinçer, Ç., Demiriz, S. ve Ergül, A., (2017). Okul öncesi dönem çocukları (36-72 ay) için özbakım becerileri ölçeği-öğretmen formunun geçerlik ve güvenirlik çalışması. Marmara Üniversitesi Atatürk Ĕgitim Fakültesi Ĕ̆itim Bilimleri Dergisi, 45, 59-78.

Johsnon, R. B. \& Christensen, L. (2014). Educational research quantitative, qualitative and mixed approaches. (5th ed.). USA: Sage Pub.

Karasar, N. (2013). Bilimsel araştırma yöntemi. Ankara: Nobel Yayın Dağıtım.

Kline, R. B. (2010). Principles and practice of structural equation modeling (3rd ed.). New York: Guilford Press.

Konya, S. (2007). Kubaşık öğrenme etkinliklerinin beş yaş grubu öğrencilerinin öz bakım becerilerini gelişimine etkisi. Yayımlanmamış yüksek lisans tezi. Adnan Menderes Üniversitesi, Sosyal Bilimler Enstitüsü, Aydın.

MEB. (2006). Okul öncesi eğitim programı (36-72 Aylık Çocuklar İçin). Ankara: MEB.

MEB. (2013). Okul öncesi eğitim programı. Ankara: MEB Temel Eğitim Genel Müdürlüğü.

Mutlu, B., Ergişi, A., Ayhan, A. ve Aral, N. (2012). Okul öncesi dönemde Montessori eğitimi. Ankara Sağllk Bilimleri Dergisi, 1, 113-128.

Oktay, A. (2002). Yaşamın sihirli yılları okul öncesi dönem. İstanbul: Epsilon Yayınevi.

Oktay, A. (2006). Okul öncesi eğitimden ilköğretime geçiş projesi. Avrupa Birliği Sürecinde Okul Öncesi Ë̆itimin Geleceği Sempozyumu Bildiri Kitabl, 75-95.

Sarı, O. (2003). 6-9 yaş zihinsel engelli çocukların annelerine öz bakım ve bazı temel becerileri kazandırmak için bir eğitim programı. Yayımlanmamış yüksek lisans tezi. Marmara Üniversitesi, Eğitim Bilimleri Enstitüsü, İstanbul.

Senemoğlu, N. (1994). Okul öncesi eğitim programları hangi yeterlilikleri kazandırmalıdır. Hacettepe Üniversitesi Eğitim Fakültesi Dergisi, 10, 21-30. 
Şimşek, Ö. F. (2007). Yapısal eşitlik modellemesine giriş: Temel ilkeler ve LISREL uygulamaları. Ankara: Ekinoks.

Ungar, M., Ghazinour, M. \& Richter, J. (2013). Annual Research Review: What is resilience within the social ecology of human development? Journal of Child Psychology and Psychiatry, 54, 348-366.

Varol, N. (2014). Öz bakım becerilerinin öğretimi. Ankara: Kök Yayıncılık.

Varol, N. (2005). Beceri ögretimi ve öz bakım becerilerinin kazandırılmasl. Ankara: Kök Yayıncılık.

Vuran, S. (1989). Zihinsel engelli çocukların giyinme becerilerinde yapabildiklerine dayall olarak hazırlanan öğretim materyalinin etkinliliği. Yayımlanmamış yüksek lisans tezi. Anadolu Üniversitesi, Sosyal Bilimler Enstitüsü, Eskişehir.

Yavuzer, H. (2005). Çocuk Psikolojisi. İstanbul: Remzi Yayıncılık.

Yılmaz, G. (2011). Yatıll ilköğretim bölge okulu 1. kademe öğrencilerine verilen öz-bakım becerileri eğitiminin ögrencilerin öz bakım becerilerine etkisi. Yayınlanmamış yüksek lisans tezi. Uşak Üniversitesi, Sosyal Bilimler Enstitüsü, Uşak. 


\section{Extended Abstract}

\section{Introduction}

The individual gains basic self-care skills in the first six years of life (Sar1, 2003). In this period, a child who has not developed self-care skills cannot participate in social and communal activities and is a burden to his/her surroundings and because he/she is under constant control, cannot find an opportunity to communicate easily with surroundings (Konya, 2007). Self-care skills that is given to the child in preschool period will be effective in considering his/her future life by confidence. The contribution of the consciously provided education has a great importance (Demiriz and Dinçer, 2003). Besides children showing normal development, it is important to apply appropriate training techniques in order for children with different development to learn self-care skills (Sar1, 2003).

As a result of the body of literature review, it was found that there were limited number of measurement tools that examined the development of self-care in children, and it was thought that the development of these measurement tools would provide more effective results. In this context, the aim of this study is to test whether the Self-Care Skills Assessment Test for 3-6 Age Children (ÖBBDT-SCSAT) is a valid and reliable measurement tool.

\section{Method}

The research is a patterned scale development and validity reliability study in general survey model. The data of the study were collected from the children attending two private and 4 formal preschool education institutions in the central districts of Konya (Meram, Selçuklu, Karatay). The schools included in the study were selected by random cluster sampling. A total of 211 children aged between 3 and 6 years were included in the study. Children participating in the study consisted of 110 girls (52.1\%) and 101 boys (47.9\%). 12 of children in the study group are three years old (5.7\%), 51 of children are four years old (24.2\%), 92 of them five years old $(43.6 \%)$, and 56 of children are six years old (26.5\%).

Self-Care Skills Assessment Test was developed to evaluate self-care skills of 3-6 yearold children. The test is answered in 5-stage Likert type consisting of very sufficient, sufficient, moderate, weak, very weak categories. Existing self-care skills measurement tools have been identified to create scale items and some items of the test have been prepared by using the items in these tools. During this study, the preschool education program prepared by MoNE (Ministry of National Education) was examined and the benefits related to self-care skills were utilized. In addition, the balance measurement tool developed for examining the effect of wearing skill measurement tool (Vuran, 1989) for pants, collared sweater and socks and effects of balance training on self-care skills was used to measure students' independent dressing skills (Demirel, 2008). Materials that are considered to be effective in providing self-care skills in children are studied. The achievements that can be obtained from these are included in the articles. The substances formed were collected in item pool. Then, similar scale items were determined by the researchers. Similar scale items were eliminated and the scale consisted of 55 items. The form prepared for the study of the scope validity was presented to the expert opinion and the number of articles with 55 has been reduced to 50 considering the recommendations of the experts. 
The validity of the Self Care Skills Assessment Test was examined by using the content validity and construct validity methods. Test-retest reliability and split-half-test reliability were used for the reliability study of the Self-Care Skills Assessment Test. Data were analyzed by using SPSS 22.0 and LISREL 8.80 data analysis package program.

\section{Results, Conclusion and Discussion}

The aim of this study was to investigate the validity and reliability of the Self-Care Skills Assessment Test for children aged three to six years. Content validity and construct validity methods were used in the validity of the test. In the scope validity study, expert opinion was applied and all the experts stated that the test was suitable for measuring self-care skills of children. In accordance with the recommendations made, the test articles were reduced from 55 to 50 items. In the construct validity of the test, factor analysis technique and confirmatory factor analysis were used. The suitability of the data for factor analysis was tested with the Kaiser-Meyer-Olkin (KMO) coefficient and the Bartlett Sphericity Test. It was concluded that the size of the study group was adequate and sufficient for factor analysis. In the study, the KMO coefficient value of the Self Care Skills Assessment Test was calculated as .837 and ChiSquare Test statistics were significant. According to the results, the data were found to be suitable for factor analysis. In order to reveal the factors of the test, factor analysis was performed based on the Principal Component Analysis and after the analysis it was found that there were 6 factors larger than 1. In addition, it was concluded that the evaluation of the scale in six sub-dimensions would give healthier results in the scope validity study. The Maximum Likelihood Verification Factor Analysis was used to test the eligibility index of the Self Care Skills Assessment Test and eight data compliance indexes were calculated. Following confirmatory factor analysis, the following values were calculated; Chi-Square $\left(X^{2}\right)$ value 1371.54, Degree of Freedom (Sd) 1159, Ratio of Chi-Square to Degree of Freedom ( $\left.\mathrm{X}^{2} / \mathrm{Sd}\right)$ 1.183, Mean Square root of Approximate Errors (RMSEA) 0.032, Goodness Fit Index (GFI) 0.94, Adjusted Goodness Fit Index (AGFI) 0.84, Comparative Fit Index (CFI) 0.95 and the Non-Normed Fit Index (NNFI) of 0.95. Although the acceptable degree of eligibility varies according to different sources, there is no standard interpretation for $\mathrm{X}^{2}$ and $\mathrm{Sd}$. However, the generally accepted general rule is that smaller values are better fitted. The $\mathrm{X}^{2} / \mathrm{Sd}$ index is expected to be smaller than five for a reasonable degree of compliance (Brown, 2006). GFI, CFI, NFI, NNFI values are expected to be higher than .90 or above. The AGFI value is expected to be higher than or equal to .80 (Anderson and Gerbing, 1984). Thus, the fit index values obtained showed that the scale items were appropriately determined for subtests.

Internal coefficient of consistence, test-retest reliability and split half-test reliability were used for the reliability study of the Self Care Skills Assessment Test. The Cronbach Alpha formula was used to calculate the internal coefficient of consistency of the Self Care Skills Assessment Test. The reliability coefficient for the three-year-old children was found to be 88 , reliability coefficient calculated for the four-year-old children was found to be .80 , reliability coefficient calculated for five years old children was found to be .85 , reliability coefficient calculated for six years of children was found to be .85 based on this information, it can be said that the internal consistency of the Self Care Skills Assessment Test has the appropriate values and is a reliable measurement tool. 
Within the scope of the procedures for the reliability of the Self-Care Skills Assessment Test, test-retesting test was conducted to check whether or not met the criteria of determinedness of time. The test was reintroduced into 29 five year-old children four weeks after the first application and the intermittent re-correlation of the test was .85. Spearman Brown correlation coefficients were calculated within the split half coefficient reliability of the test. correlation coefficient was determined as .79 for three years, it was determined as .82 For four years, was determined to be .83 for five years, and .88 correlation coefficient was founded for six years. In addition, the Spearman Brown correlation coefficients obtained increases in parallel with the age of the children. This can be explained by the principle that development, each area has progressed at different speeds in different periods and there is a sequence in development (Berk, 2006; Ungar, Ghazinour and Richter, 2013). Overall result of the research; The Self Care Skills Assessment Test is a valid and reliable measurement tool for measuring the self-care skills of children aged three to six. 